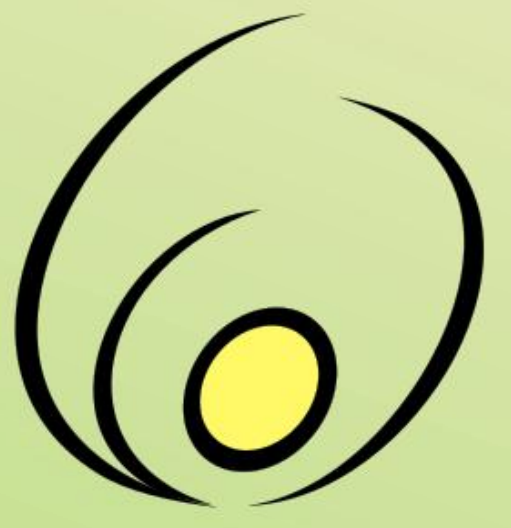

Fórum de

\section{Pró-Reitores}

\section{de Extensão}

\section{das Instituições}

\section{Públicas de}

\section{Educação Superior}

\section{Brasileiras}

Revista Brasileira de Extensão Universitária

v. 6, n. 2, p.77-85 jul-dez. 2015 e-ISSN 2358-0399

\title{
Escrevendo os Caminhos da Extensão Universitária
}

\section{na UNILA}

\author{
Ângela Maria de Souza ${ }^{1}$ \\ Noemi Ferreira Felisberto Pereira ${ }^{2}$
}

Resumo: Esse artigo possui como objetivo principal analisar o processo de consolidação da Extensão na UNILA - Universidade Federal da Integração LatinoAmericana. A proposta do artigo consiste em compreender e analisar os instrumentos elaborados durante o processo de construção de documentos estruturantes da Extensão da UNILA, bem como as orientações e diretrizes que balizaram seu surgimento, no sentido de apresentar a concepção de extensão adotada, bem como os caminhos percorridos quando de sua construção. Neste sentido, através de levantamento documental, pesquisa bibliográfica e da participação cotidiana no trabalho extensionista, fez-se um levantamento das estratégias, procedimentos e dos princípios que possibilitaram a elaboração destes documentos que criam as diretrizes para as Ações de Extensão da UNILA. Conclui-se que a Política de Extensão Universitária da UNILA, bem como outros documentos relacionados, foram construídos a partir de discussões de atores sociais ativos e corresponsáveis pelo conteúdo e resultados auferidos pela extensão universitária. Evidenciou-se, ainda, que isso repercutiu no avanço qualitativo e, consequentemente, quantitativo, das ações extensionistas no período de 2010-2015.

Palavras-chave: Extensão Universitária, Política de Extensão, Integração.

\section{Writing the Paths of the University Extension Program at UNILA}

Abstract: This paper has as main objective to analyze the consolidation process of the university extension program at UNILA - Universidade Federal da Integração Latino-Americana. The purpose was to analyze and to understand the tools developed during the process of structuring documents of the UNILA's University Extension programs, and the guidelines and directives that guided its emergence, as well as to present the design adopted and the paths followed during its conception. In this sense, by means of archival work, literature and daily participation in extension activities, a survey was carried out to assess the strategies, procedures and principles that made possible the design of these documents and create the guidelines for extension projects at UNILA. It has been concluded that the University Extension Policy at UNILA, as well as other related documents, was conceived from discussions of active and co-responsible social actors for the content, and the results obtained by the university extension Furthermore, it was also evident that these measures reflected in the qualitative, and therefore, quantitative improvement of the extension actions in the 2010-2015 period.

Key-words: University Extension, Extension Policy, Integration.

1 Universidade Federal da Integração Latino-Americana. Pró-Reitora de Extensão. Docente no Curso de Antropologia e no Programa de PósGraduação Interdisciplinar em Estudos Latino Americanos -IELA. angela.souza@unila.edu.br

2 Responsável pela Divisão de Acompanhamento das Ações de Extensão da PROEX (2013 a 2015). Mestranda do Programa de Pós-Graduação strictu sensu em Sociedade, Cultura e Fronteiras da Universidade Estadual do Oeste do Paraná UNIOESTE. Rua Áustria, 291, Jardim Europa. CEP: 85.859-316. Foz do Iguaçu-PR. noemi.ferreira@unila.edu.br (autora para correspondência) 


\section{Escribiendo los Caminos de la Extensión Universitaria en UNILA}

Resumen: Este trabajo tiene como objetivo principal analizar el proceso de consolidación de la extensión en UNILA Universidade Federal da Integração Latino-americana. La propuesta del artículo consiste en comprender y analizar las herramientas desarrolladas durante el proceso de construcción de los documentos estructurantes de Extensión Universitaria de UNILA, y las directrices y directivas que guiaron su emergencia, con el fin de presentar el diseño y los caminos seguidos durante su construcción. En este sentido, a través de una encuesta documental, de investigación bibliográfica y de la participación diaria en el trabajo de extensión, se ha hecho un estudio de las estrategias, de los procedimientos y de los principios que hicieron posible la preparación de estos documentos que crearon las directrices para las acciones de extensión de UNILA. Se ha concluido que la Política de Extensión Universitaria de UNILA, así como otros documentos relacionados, fueron construidos a partir de las discusiones de los actores sociales activos y corresponsables por el contenido y los resultados obtenidos por la extensión universitaria. Fue evidente también que esto se reflejó en la mejora cualitativa y por lo tanto cuantitativa de las acciones de extensión universitaria en el período 2010-2015.

Palabras-clave: Extensión Universitaria, Política de Extensión, Integración.

\section{Introdução}

A política de expansão do ensino superior implementada no Brasil durante os governos dos presidentes Luiz Inácio Lula da Silva e Dilma Rousseff (2002 - 2014) deram origem a 14 (catorze) novas Universidades. Dentre essas, foi criada pela Lei $12.189 / 10$, no âmbito do poder executivo, a Universidade Federal da Integração Latino-Americana (UNILA), com a missão de contribuir para a integração solidária na América Latina e Caribe.

Diferentemente das outras instituições idealizadas para expandir e interiorizar o ensino superior, a UNILA tem por vocação "ser uma universidade cuja missão será a de contribuir para a integração latino-americana, com ênfase no Mercosul, por meio do conhecimento humanístico, científico e tecnológico e da cooperação solidária entre as universidades, organismos governamentais e internacionais" (IMEA, 2009, p. 9).

A instituição pretende alcançar seus objetivos por meio da geração, transmissão, difusão e aplicação de conhecimentos produzidos pela indissociabilidade entre ensino, pesquisa e extensão; e com a formação de cidadãos que, além de competentes nos diferentes campos do conhecimento, estejam comprometidos com a busca de soluções acadêmicas, científicas e tecnológicas para os problemas da América Latina e Caribe, de acordo com a Política de Extensão Universitária da UNILA (UNILA, 2014b).

O diferencial dessa instituição está, além de sua missão, na abrangência do público envolvido, uma vez que não se limita apenas aos brasileiros, mas inclui os demais países latino-americanos na formação de seu corpo docente e discente. Executar uma estratégia que responda simultaneamente as suas vocações educacionais nacional e latino-americana, numa região e territórios extremamente afetados por princípios capitalistas neoliberais, povoados por desigualdades e exclusões sociais (FIORI, 1997), é desafiador.

Nesse contexto, é que a extensão universitária ganha grande importância, pois ela é o elo entre a universidade e a sociedade. Assim, a extensão desempenha uma atribuição extremamente relevante na inserção da UNILA na região, desenvolvendo ações no âmbito científico, artístico e cultural que compartilham conhecimentos produzidos.

Para um exercício de reflexão sobre este contexto, o artigo está organizado em três momentos. O primeiro aborda a metodologia desenvolvida para o estudo. Já no segundo desenvolvemos um breve retrospecto dos pontos basilares que entendemos fundamentais para a extensão universitária. Em seguida, delineamos a extensão universitária da UNILA, mostrando os caminhos percorridos no desenvolvimento e implantação da Política de Extensão Universitária da UNILA.

\section{Parâmetros Norteadores}

A pesquisa bibliográfica e documental é a base deste estudo $^{1}$. A revisão bibliográfica sobre a extensão universitária se faz necessária porque "o estudo da literatura pertinente pode ajudar a planificação do trabalho e representa uma fonte indispensável de informações, podendo até orientar as indagações" (MARCONI; LAKATOS, 2003, p. 158). Esta pesquisa teve por objetivo compreender os diferentes conceitos que abrangem a extensão Universitária e suas implicações para o processo de consolidação de uma política de extensão universitária.

A análise documental utilizou como base, principalmente: Relatórios de Gestão da UNILA, Relatório da Comissão Própria de Avaliação (CPA), 
Plano de Desenvolvimento Institucional (PDI), Política de Extensão Universitária da UNILA (PUNILA), entre outros. A partir destes documentos, esta investigação averiguou as diretrizes e a concepção de extensão universitária que possibilitaram a elaboração e implantação da Política de Extensão Universitária da UNILA.

Neste sentido, torna-se importante lembrar que a UNILA foi criada com a proposta de ser uma Universidade voltada para o debate sobre as problemáticas latinoamericanas, e nasce

comprometida com o destino das sociedades latinoamericanas, cujas raízes estão referenciadas na herança da Reforma de Córdoba (1918), está voltada para o futuro visando contribuir, por meio do papel estratégico do conhecimento compartilhado na construção de sociedades sustentáveis no século XXI, fundadas na identidade latino-americana em sua diversidade cultural e orientação para o desenvolvimento, com justiça social e sustentabilidade socioambiental. (IMEA, 2009, p. 9)

Este comprometimento apontado no projeto de implantação da Universidade nos remete a uma reflexão mais intensa sobre a importância da Extensão neste contexto, tanto no sentido local, que abrange ações realizadas no espaço da fronteira entre as cidades de Foz do Iguaçu - Brasil, Ciudad del Este - Paraguai e Puerto Iguazu - Argentina, como no contexto mais amplo e transnacional, aumentando a importância da realização de intermediações e trocas de experiências extensionistas na América Latina.

\section{Extensão Universitária e a Reconfiguração Conceitual}

A Extensão Universitária passou por várias ressignificações conceituais. De acordo com Nogueira (2001), no período de 1911 a 1968, a extensão se configurou como realização de cursos, conferências e prestação de serviços realizados como atividades desarticuladas do ensino e da pesquisa. De igual forma, não era considerado o saber popular, pois a comunidade era uma mera receptora. Segundo a autora,

A extensão praticada pelos estudantes universitários, no início da década de 60, é o primeiro aceno de mudança na sua concepção. É quando se vêem ações concretas na direção do compromisso com as classes populares, não de forma assistencial, mas com a intencionalidade de conscientizá-las sobre seus direitos (NOGUEIRA, 2001, p. 62).

Essas ações, no entanto, foram reprimidas durante a Ditadura Militar e, por conseguinte, a União Nacional dos Estudantes (UNE) foi dissolvida. Nogueira (2001) afirma que mesmo com o retrocesso imposto à extensão Universitária pelo governo militar, as ideias delineadas pelos estudantes, no início dos anos 60, reapareceram e se consolidaram em discussões posteriores.

Esta nova concepção de extensão comprometida com as classes populares, com a integralidade entre extensão, pesquisa e ensino reflete um significativo avanço na primeira Política de Extensão Universitária do Brasil em 1975. Para Nogueira (2001), começou a ser considerada a relação entre ensino, pesquisa e extensão, ampliou-se as formas de como a extensão poderia se processar, e expandiu-se o público alvo das ações extensionistas. Dentro desta perspectiva, seguiu-se a discussão sobre a extensão universitária através do Fórum Nacional de PróReitores de Extensão das Universidades Públicas Brasileiras (FORPROEX) criado em 1987, dada a necessidade de institucionalização da extensão universitária. As discussões e reflexões do FORPROEX produziram/produzem uma série de documentos com diretrizes conceituais e políticas fundamentais para uma concepção de extensão dialógica, integradora e dialética, publicadas através da Coleção Extensão Universitária composta por seis documentos - e a Política Nacional de Extensão Universitária.

A partir disso, a formação acadêmica universitária pressupõe a indissociabilidade entre extensão, pesquisa e ensino, e a prática vem mostrando que, para se fazer extensão, é necessário pesquisa, e que durante o desenvolvimento da atividade extensionista é desencadeado o processo de ensino, o que garante a indissociabilidade e, consequentemente, uma formação mais humanística e integradora para os interlocutores nela envolvida. Para Maria Nogueira (2001) a

\begin{abstract}
extensão é um momento, uma etapa desse processo maior que vai desde a produção do conhecimento e sua sistematização à transmissão dos resultados. Assim ela não se caracteriza como atividade isolada do ensino e da pesquisa, ao contrário, ela é a dimensão da vida acadêmica que articula as outras duas, de forma indissociável, facilitando a interdisciplinaridade. A relação com a sociedade é necessária e indispensável, pois com ela se estabelece a troca entre o saber acadêmico e o saber popular. (NOGUEIRA, 2001, p. 69)
\end{abstract}

Para isso, se faz necessário partir de uma posição que considere uma concepção de extensão em que todos os atores sociais ensinam e aprendem, conforme nos ensina Paulo Freire (2006). Nesse sentido, alguns elementos fundamentais para o entendimento do termo extensão são apontados por Tommasino (2015):

- Processo educativo transformador sem estereótipos onde todos (educando e educador) aprendem e ensinam;

- Processo que contribui com a produção de conhecimento novo, vinculando criticamente o saber acadêmico com o saber popular;

- Processo que busca promover formas 
organizativas, associativas, grupais que podem levar a superar problemáticas significativas da sociedade;

- Processo que permite orientar linhas de investigação e planos de aulas;

- Processo que gera compromisso da universidade com a sociedade;

- Processo que em sua dimensão pedagógica constitui uma metodologia de aprendizagem integral e humanizadora;

- Processo que exige participação e envolvimento de todos os atores sociais e universitários nas etapas de planejamento, execução e avaliação;

- Processo que demanda a comunicação dialógica com o outro;

- Processo que demanda abordagem interdisciplinar;

- Processo que leva em consideração os tempos dos atores sociais envolvidos.

Esses elementos são essenciais dentro de uma ação extensionista para que exista a produção do conhecimento e o envolvimento real de todos os atores. Paulo Freire (2006) nos ensina que

O conhecimento exige uma presença curiosa do sujeito em face do mundo. Requer sua ação transformadora sobre a realidade. Demanda uma busca constante. Implica em invenção e em reinvenção. Reclama a reflexão crítica de cada $\mathbf{u m}^{2}$ sobre o ato mesmo de conhecer, pelo qual se reconhece conhecendo e, ao reconhecer-se assim, percebe o "como" de seu conhecer e os condicionamentos a que está submetido seu ato. (FREIRE, 2006, p. 16).

Nessa perspectiva, a existência do diálogo é imprescindível para não existir a invasão do espaço do outro, para que não exista a superioridade de uns dos sujeitos sobre outros transformando pessoas em "coisas" 3 , de modo a desconsiderar o homem como ser histórico e a problematização dialógica a ela inerente. Assim, para que exista o respeito com a comunidade envolvida na ação extensionista é que precisamos do dialógico, pois "ser dialógico é não invadir, é não manipular, é não sloganizar. Ser dialógico é empenhar-se na transformação constante da realidade" (FREIRE, 2006, p. 28), excluindo toda relação na qual pessoas podem ser transformadas em objetos.

Portanto, para se fazer extensão deve-se partir do princípio de que não existe hierarquia entre os conhecimentos produzidos na universidade e o conhecimento popular. Assim, a extensão deve ser concebida no sentido de retroalimentação e troca de saberes com a participação dos agentes populares como sujeitos ativos e corresponsáveis pelo conteúdo e resultados auferidos pela extensão universitária.

\section{Extensão na UNILA}

A Extensão da UNILA começou seus trabalhos no segundo semestre de 2010, concomitantemente com as demais atividades acadêmicas. A Universidade contava com aproximadamente 200 alunos oriundos do Brasil, Paraguai, Uruguai e Argentina, subdivididos em seis cursos de graduação. Essa primeira comunidade acadêmica formada em agosto de 2010 foi a precursora de toda a discussão política acerca dos rumos da nova Instituição.

Foi um começo que demandava debates em torno da concepção na qual se alicerçaria a extensão na UNILA, bem como quais os objetivos que ela perseguiria. Dessa forma, a grande atividade que se apresentou como resultado do trabalho da extensão em 2010 foi o festival "Nuestra América", espetáculo apresentado como atividade de encerramento do Módulo I do curso de extensão de capacitação técnica em música construída em parceria com a Universidade de Brasília (UnB) ${ }^{4}$.

A atividade teve grande repercussão nos grupos artísticos da comunidade da fronteira trinacional e também no fortalecimento da UNILA com sua vocação LatinoAmericana, pois buscou "explorar e recuperar as manifestações culturais que mais influenciaram a história e a consolidação política da América Latina" (UNILA, 2014a, p.60).

Já em 2011, iniciou-se a elaboração de documentos que expressavam as diretrizes gerais para a política de extensão da Universidade. Entre eles a publicação da Portaria/UNILA n ${ }^{\circ}$ 76/2011, que instituiu o Programa de Bolsas de Extensão da UNILA - PROBEX - que estabeleceu como seus objetivos:

Incentivar a participação de Discentes, Servidores Técnico-Administrativos em Educação e Docentes nas atividades de extensão da UNILA; estimular o desenvolvimento da criatividade na busca da socialização de saberes, aprimorando o processo formativo de profissionais enquanto cidadãos; viabilizar a relação transformadora entre a universidade e a sociedade, priorizando as demandas de relevância social, com o intuito de melhorar as condições de vida das comunidades beneficiadas; proporcionar ao bolsista a aprendizagem de técnicas e métodos de pesquisa e de ações social e cultural, bem como estimular o desenvolvimento do pensar cientificamente e da criatividade, decorrentes das condições criadas pelo confronto direto com problemas sociais (UNILA, 2011).

No mesmo documento foi instituído o Comitê Assessor de Extensão (CAEX), o primeiro órgão colegiado com representação de todas as categorias da comunidade acadêmica: discente, docente e técnico administrativo, envolvidos de alguma maneira com atividades extensionistas. Uma das principais atribuições do CAEX era criar a política de administração do PROBEX.

A partir da instituição do CAEX e do PROBEX, a 
extensão da UNILA começou a desenvolver ações visando integrar alunos e a comunidade na qual ela se insere. Para tanto, promoveu eventos e intervenções que geraram a integração entre os diversos atores da comunidade.

Além disso, o CAEX aprovou os primeiros editais para seleção de programas e projetos de extensão, para os quais a PROEX destinou verbas orçamentárias para o pagamento de bolsas de extensão aos alunos, além de outros recursos. Dessa forma, apareceram os primeiros indicadores da universidade relacionados à dimensão de extensão. Foram 17 projetos com 29 bolsistas envolvidos, de acordo com o Relatório de Gestão 2011 (UNILA, 2011).

Portanto, baseado na socialização de saberes, no processo formativo de profissionais enquanto cidadãos, na priorização das demandas sociais e na relação transformadora entre a universidade e sociedade, a extensão da UNILA teve seus primeiros projetos e programas desenvolvidos após a instituição do CAEX.

Em 2012, as ações extensionistas continuaram a crescer, norteadas pelos documentos da coleção "Extensão Universitária”, publicada pelo Fórum de Pró-Reitores de Extensão - FORPROEX, além da Portaria n ${ }^{\circ}$ 076/2011 citada acima. Dessa forma, os primeiros conceitos de extensão universitária começaram a ser defendidos dentro dos documentos oficiais da UNILA. No Relatório de Gestão, apresentado aos órgãos de controle, encontramos que a extensão universitária é

um processo interdisciplinar, educativo, cultural, científico e político que se operacionaliza em ações institucionais e projetos, conduzindo à reflexão e discussão sobre o espaço social e os sujeitos nele envolvidos. A Extensão da UNILA objetiva o desenvolvimento sustentável e a transformação social; prepara o corpo docente e discente para integrar o conhecimento científico e o da comunidade num processo dialógico permanente; une conhecimentos teóricos e práticos no levantamento dos problemas da comunidade da região da fronteira trinacional e da integração e desenvolvimento dos países latino-americanos; promove a inclusão social por meio da construção e socialização do conhecimento e da integração de cultura, esporte e lazer; e privilegia realizações conjuntas entre universidade, administrações públicas e sociedade civil. (UNILA, 2013a, p.25)

Observa-se que o conceito está ligado aos objetivos da Portaria/UNILA nº 076/2011, com relação ao estímulo ao desenvolvimento da criatividade; a busca da socialização de saberes; a busca pela relação transformadora entre a universidade e sociedade. Mas tal conceito vai mais além, incorporando a missão da UNILA de contribuir para a integração latino-americana.

Assim, em 2012 foram desenvolvidas 40 ações de extensão, sendo 33 projetos e 13 programas. O diferencial é que o alcance das ações é muito maior com projetos sendo desenvolvidos em toda a região trinacional: Argentina, Brasil e Paraguai, sendo este um dos propósitos apontados desde o processo de criação da Universidade. Porém, mais do que a fronteira entre as três cidades, o objetivo é a ampliação deste contexto de abrangência, tanto com ações efetivas, como também com as trocas de experiências de outras Universidades latino americanas, e que possibilitem um processo de integração dialógico e permanente.

A expansão das atividades continuou no ano de 2013, com 37 projetos, 27 cursos e 12 programas de extensão desenvolvidos em toda a região de fronteira. Todavia, nascia também a necessidade do amadurecimento dos conceitos do que se entendia por ação de extensão, bem como das definições sobre as principais linhas de atuação da extensão da UNILA.

É necessário salientar que, nesse período, toda a Instituição estava em expansão, com novos desafios e com questões estruturais e institucionais sendo definidas. Neste contexto, os órgãos colegiados previstos no Regimento Interno da UNILA - entre eles a Comissão Superior de Extensão, que substituiu o CAEX- foram empossados em novembro de 2013.

A Comissão Superior de Extensão (COSUEX) é um órgão consultivo, normativo e deliberativo, com atribuições e funcionamento que foram definidos no próprio Regimento Geral da Universidade. O escopo de atuação da COSUEX é muito superior ao antigo órgão colegiado que assessorava a PROEX. De acordo com o artigo 34 do Regimento Geral, cabe à COSUEX

I. Fixar normas gerais para a organização,
funcionamento, avaliação e alterações dos
programas de extensão; II. Estabelecer normas e
critérios para a concessão de bolsas de extensão; III.
Regulamentar a legislação e as normas superiores
de sua competência; IV. Apreciar, em grau de
recurso, decisões de instâncias inferiores sobre
matérias de competência desta Comissão; V.
Deliberar e acompanhar programas de mobilidade
acadêmica, nacionais e internacionais; VI. Deliberar
ou opinar sobre outras matérias de sua competência.
(UNILA, 2013b, p. 16-17)

Ainda no ano de 2013, tivemos o I Seminário de Extensão da UNILA - SEUNI, com os objetivos de apresentar os resultados das ações de extensão 2012/2013 e promover espaços de diálogo e socialização de conhecimento, estreitando laços com a comunidade ${ }^{5}$. Como resultado deste diálogo entre as ações extensionistas e a Comunidade Acadêmica e Externa, o evento suscitou discussões e diretrizes determinantes para a realização do segundo evento.

Esses acontecimentos apontaram o ano de 2014 como um marco decisivo na definição de uma política de extensão criada a partir das propostas do FORPROEX, mas que fosse consonante com as necessidades específicas da UNILA. Por isso, era imprescindível discutir estratégias para acelerar o processo de institucionalização da extensão, entendendo sua peculiaridade como uma universidade voltada para a integração Sul-Sul ${ }^{6}$.

Nesse contexto, foi organizado pela PROEX 
conjuntamente com a COSUEX o "II SEUNI: escrevendo os caminhos da extensão na UNILA" que ocorreu nos dias 12 e 13 de maio de 2014, baseado nas temáticas e discussões levantadas no I SEUNI. O evento foi organizado com base na metodologia que promoveu a ampla participação da comunidade acadêmica e dos diversos setores sociais da região de fronteira trinacional.

As atividades foram divididas em palestras com convidados $^{7}$ e discussões em grupos de trabalhos coordenados por integrantes da PROEX e da COSUEX. Ao todo foram seis grupos de trabalho (GT) que após a palestra de abertura sobre a institucionalização da extensão e a apresentação do panorama da extensão na UNILA, abordaram as temáticas:

\section{- GT1 Extensão na UNILA;}

- GT2 Áreas temáticas e programas de extensão;

- GT3 Normatização das ações de extensão;

- GT4 Institucionalização da extensão;

- GT5 Extensão na Fronteira;

- GT6 Extensão na comunidade;

A partir das discussões e debates, cada GT produziu um documento com apontamentos que foram levados à plenária final para encaminhamentos. Tais apontamentos serviram de fundamentos para a elaboração da minuta da Política de Extensão da UNILA, realizada conjuntamente entre PROEX e COSUEX. Em setembro de 2014, depois de ampla discussão e participação em sua elaboração, foi aprovada, por meio da Resolução COSUEX nº 003/2014, a Política de Extensão Universitária da UNILA (PEUNILA).

A PEUNILA está orientada pelas as diretrizes propostas pelo FORPROEX (2012), quais sejam: Interação Dialógica; Interdisciplinaridade e Interprofissionalidade; Indissociabilidade Ensino-Pesquisa-Extensão; Impacto na Formação do Estudante; Impactos e Transformação Social. E trouxe como conceito que

Extensão é a ponte entre a Universidade e a Comunidade. Constitui-se como processo educativo, cultural, científico e político que, articulado de forma indissociável com o ensino e a pesquisa, viabiliza e media a relação transformadora entre a Universidade e a Sociedade. Tal processo apoia-se na troca de saberes para evitar e resolver problemas e no diálogo entre a função social da Universidade e as Políticas Públicas, buscando a efetivação de direitos sociais e da plena cidadania, de forma articulada ao combate a discriminações, preconceitos e desigualdades, e em acordo com as políticas de ações afirmativas e de inclusão social, partindo do contexto de fronteira entre Brasil - Foz do Iguaçu, Argentina - Puerto Yguazu e Paraguai - Ciudad del Este. Assim, a extensão é um meio eficiente para colaborar na criação de redes de conhecimento latino-americano e para a inclusão de atores sociais locais, bem como para própria inserção dos estudantes na comunidade. (UNILA, 2014b, p. 3)

A consolidação da PEUNILA, norteada pelas particularidades da Instituição, pressupõe a troca de saberes com atores sociais de toda América Latina em uma relação horizontal, partindo do contexto de fronteira, para a construção do conhecimento considerando que as dimensões Extensão, Ensino e Pesquisa são formas indissociáveis na produção do conhecimento.

\section{A Consolidação da Extensão Universitária}

O ano de 2014 marcou a elaboração de três importantes documentos para a Extensão da Universidade: a Política de Extensão da UNILA; o Regulamento da Extensão Universitária da UNILA $^{8}$; o Regimento interno da COSUEX $^{9}$. Estes documentos possibilitam uma maior abrangência das ações, bem como uma ampliação no alcance de compreensão sobre o que é e qual o papel da Extensão no contexto de formação acadêmica. Este ano também marca a definição de criação de novos cursos de graduação na UNILA que possibilitou maior abrangência nas áreas temáticas da Extensão Universitária.

Outro fator importante para o desenvolvimento das ações extensionistas foi Programa de Fomento a Projetos Inovadores na Área de Extensão (PROFIEX) que tem como objetivos: garantir meios institucionais aos coordenadores das ações de extensão no desenvolvimento de atividades de extensão; viabilizar o financiamento ágil das ações de extensão em áreas prioritárias de atuação da Universidade; fortalecer e ampliar as ações de extensão aprovadas; apoiar as ações de extensão de visibilidade e relevância social.

Com este cenário, foi possível aumentar o número de projetos desenvolvidos ${ }^{10}$. Foram 62 ações que contemplaram todas as áreas temáticas (Figura 1).

Já com relação aos programas de extensão, em razão da definição das áreas prioritárias em que os mesmos deverão atuar e do próprio conceito estabelecido na PEUNILA em 2014, com exceção do Programa Ingressa - aprovado pelo PROEXT/2014- houve um importante processo de reestruturação dos mesmos. E como um dos resultados do II SEUNI, ficou estabelecida a continuidade de discussões até o estabelecimento de diretrizes que pudessem possibilitar a criação de Programas, conformes os documentos norteadores.

Neste ano, 2015, com a publicação da PEUNILA e com o auxílio financeiro institucionalizado pelo PROFIEX, as propostas de ações extensionistas tiveram um aumento bastante significativo, alcançando 121 ações aprovadas (Figura 1). 


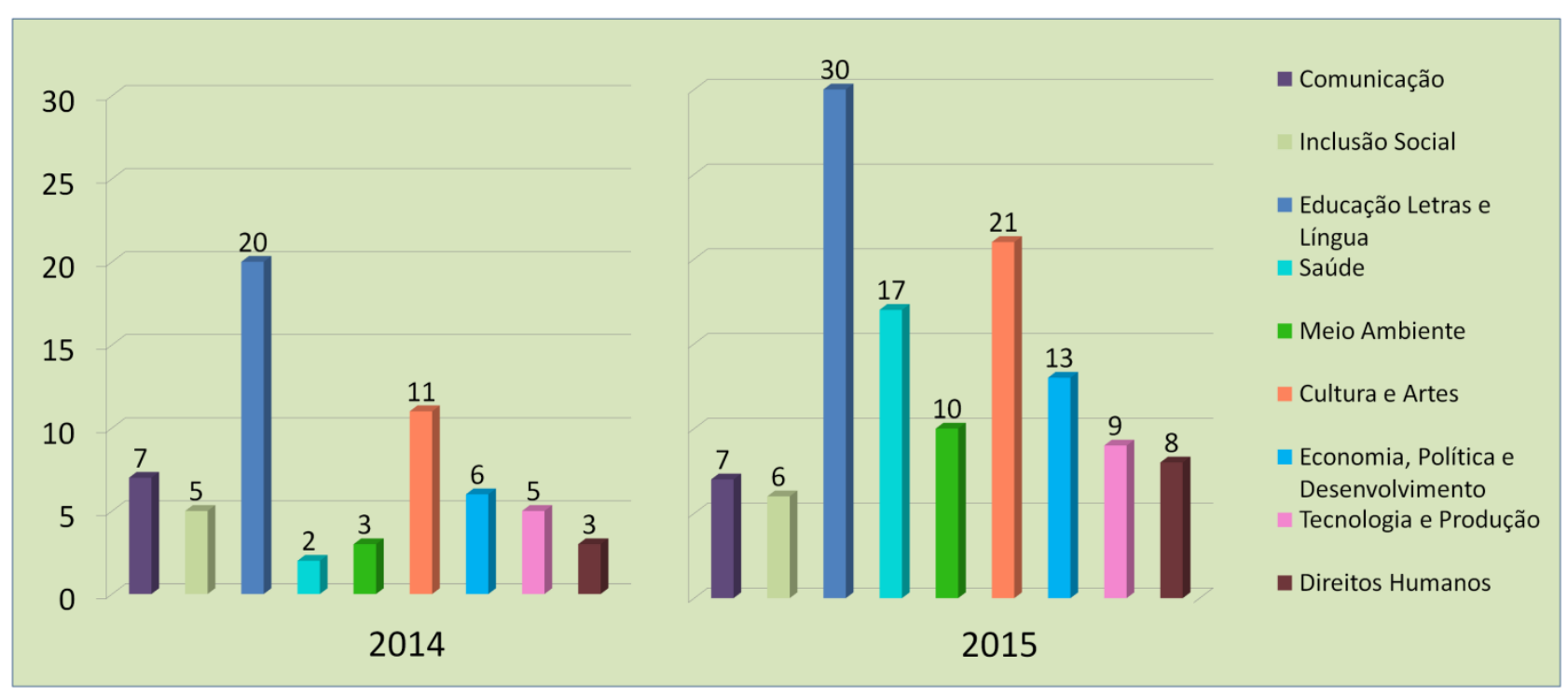

Figura 1. Ações de Extensão por área temática na UNILA - Universidade da Integração Latinoamericana, em 2014 e 2015.

Fonte: Pró-Reitoria de Extensão/ UNILA (2014a, 2015).

É possível visualizar que o aumento de ações de extensão ocorreu em todas as áreas temáticas. $\mathrm{Na}$ área de saúde, o acréscimo foi bastante expressivo comparado com o ano de 2014. Isso se deve a institucionalização da extensão por meio de documentos estruturantes e a criação do curso de medicina no segundo semestre de 2014 que visa formar profissionais qualificados para o atendimento das demandas a área da saúde em conformidade com a realidade dos povos latino-americanos e segundo uma concepção que inclui uma perspectiva humanista e social da atuação profissional voltada à promoção da saúde.

Outro fator importante é a ocorrência de um número maior de ações nas áreas de "educação, letras e línguas" e "cultura e artes" tanto em 2014 como em 2015. Depreende-se que isso ocorre por ser uma universidade orientada pelo bilinguismo e o multiculturalismo, e que busca a integração latino-americana.

Nesse contexto, a UNILA recebe alunos e professores de vários países da América Latina com culturas e línguas próprias que, no cotidiano acadêmico, acabam por propiciar ambientes interculturais que se refletem nas ações de extensão. Salienta-se, também, que a própria região de fronteira trinacional - Argentina, Brasil, Paraguai - em que a Instituição está inserida torna possível constatar que as trocas linguísticas e culturais acontecem de maneira bastante intensa.

\section{Considerações Finais}

A extensão é uma dimensão que, juntamente com o ensino e a pesquisa, estrutura o processo de formação acadêmica em diálogo com comunidade em geral, uma vez que ela é o elo entre a universidade e a sociedade, a qual proporciona a troca de saberes acadêmico e popular.
Isso deve acontecer numa relação horizontal, sem hierarquia entre os conhecimentos produzidos no meio acadêmico e o conhecimento popular, sendo esta uma perspectiva relativamente recente. Ela surgiu das discussões de estudantes no início dos anos 1960 que demandavam uma extensão universitária que integrassem as dimensões ensino, pesquisa e extensão, porém teve uma interrupção com o regime militar e retorna com novas discussões a partir do processo de redemocratização do país.

Apesar da repressão sofrida durante o período da Ditadura Militar, as ideias dos estudantes reapareceram no FORPROEX, que produz uma série de documentos de referencia nacional, na qual a extensão é considerada a partir da indissociabilidade entre pesquisa e ensino; da troca de saberes; da relação transformadora entre universidade e sociedade; da interdisciplinaridade; da relação dialógica; no reconhecimento e respeito do saber popular; na horizontalidade.

Essas diretrizes foram fundamentais para a construção da Política de Extensão Universitária da UNILA e demais documentos, pois a partir de uma metodologia participativa, aberta a discussões de todos os atores sociais, é que se sedimentou que a extensão desempenha uma atribuição definidora na inserção da UNILA na região, desenvolvendo ações no âmbito científico, artístico e cultural que compartilham conhecimentos produzidos.

Assim, a PEUNILA foi concebida com um sentido de retroalimentação e troca de saberes com a participação dos agentes populares como sujeitos ativos e corresponsáveis pelo conteúdo e resultados auferidos pela extensão universitária, conforme nos ensinou Paulo Freire (2006). Foi neste esforço conjunto que observamos a evolução das ações extensionistas no período de 2010-2015, com grande destaque para o ano 
de 2014 com a produção de documentos estruturantes da extensão da Universidade.

Essa concepção de extensão possibilita que a missão da UNILA no sentido de dialogar sobre a integração latino americana, a diversidade cultural, o bilinguismo e orientação para o desenvolvimento social e econômico da América Latina, o trabalho na direção da superação da ideia de fronteira nacional como uma barreira onde o país termina e se apoie numa percepção deste contexto como espaço de fluxos, diálogos, trocas, intermediações que são determinantes para a Extensão da Unila nos desafios que enfrenta.

Portanto, a extensão na UNILA busca aproveitar as riquezas intralinguísticas e culturais que possui a comunidade da região da fronteira, bem como as trazidas pelos docentes e discentes de toda América Latina e o conhecimento científico para se consolidar como um fazer acadêmico articulador, transformador, emancipatório e democrático.

\section{Agradecimentos}

Agradecemos todos os diálogos realizados com os diferentes interlocutores na Pró-Reitoria de Extensão através da Coordenadoria, dos Departamentos, das Divisões; na COSUEX - Comissão Superior de Extensão; nos SEUNIs - Seminários de Extensão da UNILA; com a Comunidade Externa. Estes espaços foram determinantes para dinamizar o debate sobre a Extensão na/da UNILA, possibilitaram a elaboração de importantes documentos estruturantes da Extensão da Universidade e estimularam o processo de escrita deste artigo.

\section{Notas}

1. Além de pesquisa bibliográfica e documental, destaca-se a atuação das pesquisadoras junto à extensão universitária e junto aos órgãos colegiados ligados a Pró-Reitoria de Extensão. Isso possibilitou uma aproximação com o cotidiano da extensão universitária, bem como essa análise como sujeitos participantes.

2. Grifos das autoras.

3. Paulo Freire explica que a coisificação ocorre quando um sujeito impõe sua visão sobre os demais. Para o autor se isso ocorrer ele "estará prescrevendo suas opções aos demais; ao prescrevê-las, estará manipulando; ao manipular, estará 'coisificando' e ao coisificar, estabelecerá uma relação de 'domesticação' que pode, inclusive, ser disfarçada sob roupagens em tudo aparentemente inofensivas." (FREIRE, 2006, p.53)

4. Luisa Maria Nunes de Moura e Silva foi a primeira PróReitora de Extensão da UNILA (2010 -2012) e dirigiu as primeiras atividades e discussões sobre a extensão na UNILA.

5. A conferência de abertura intitulada "Educação para a Cidadania e Extensão Universitária" foi ministrada pela Prof $^{\text {a }}$ Gisele Quimelli, coordenadora Regional do FORPROEX-Sul e Pró-Reitora de Extensão da Universidade Estadual de Ponta Grossa (UEPG). A programação do evento incluiu também mesas de debate, sessões de comunicações orais e de pôsteres, além de apresentações artísticas e mostra audiovisual.

6. Integração Sul-Sul especialmente entendida a partir da intensificação de diálogos, parcerias e acordos com países e regiões como América Latina e países do continente Africano. Diferencia-se por mudar a direção destas relações que vão muito além de acordos econômicos.

7. A Conferência de abertura intitulada "Institucionalização da Extensão" foi ministrada pela Téc. em Assuntos Educacionais e Prof ${ }^{a}$. Maria das Dores Pimentel Nogueira, Pró-Reitora adjunta de Extensão da Universidade Federal de Minas Gerais (UFMG), coordenadora do Programa Pólo de Integração da UFMG no Vale do Jequitinhonha desde 1996, membro do FORPROEX.

8. O Regulamento da Extensão Universitária da UNILA foi elaborado e discutido em 2014 e publicado pela Resolução COSUEX $n^{\circ} 001$ de 25 de fevereiro de 2015.

9. O Regimento da COSUEX foi elaborado e discutido em 2014 e está em fase final de tramitação no Conselho Superior da Universidade (CONSUN) aguardando aprovação.

10. Especialmente no ano de 2014, foram realizadas oficinas e cursos direcionados a comunidade acadêmica (docentes, discentes e TAEs) com o objetivo de ampliar o conhecimento sobre os documentos norteadores da Extensão; apresentar e estabelecer fluxos e instrumentos de acesso a recursos e institucionalização das ações de extensão; explicar procedimentos para proposição e cadastro no SIGAA de ações de extensão e, principalmente, para trabalhar a concepção de extensão delineada na PEUNILA. Estas ações contribuíram de forma significativa para o aumento no número de ações dentro dessa nova compreensão da extensão.

\section{Referências}

BRASIL. Lei n ${ }^{\circ} 12.189$, de 12 de janeiro de 2010. Dispõe sobre a criação da Universidade Federal da Integração LatinoAmericana - UNILA e dá outras providências. Diário Oficial da União, 13 de Jan. 2010. Seção 01, página 01. Disponível em: < http://www.planalto.gov.br/ccivil_03/_ato2007-

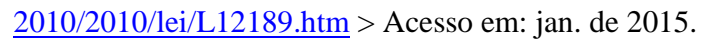

FIORI, J. L. Neoliberalismo e políticas públicas. In: FIORI, J. L. Os moedeiros falsos. Petrópolis, Rio de Janeiro: Vozes, 1997.

FREIRE, P. Extensão ou Comunicação. 13 ed. São Paulo: Paz e Terra, 2006.

GIL, A. C. Métodos e técnicas de pesquisa social. 4. ed. São Paulo: Atlas, 2002.

IMEA - Instituto Mercosul de Estudos Avançados. COMISSÃO DE IMPLANTAÇÃO DA UNILA. Unila em construção: um projeto universitário para a América Latina. Foz do Iguaçu, PR: IMEA, 2009.

MARCONI, M. A.; LAKATOS, E. M. Fundamentos de metodologia científica. 5. ed. São Paulo: Atlas, 2003.

MINAYO,M. O. de S. (Org.). Pesquisa Social: Teoria, método e criatividade. 22. ed. Petrópolis: Vozes, 2003.

NOGUEIRA, M. das D. P. Extensão Universitária no Brasil: uma Revisão Conceitual. In: FARIA, D. S. (Org). Construção 
Conceitual da Extensão na América Latina. Brasilia: UNB, 2001.

SEVERINO, A. J. Expansão do ensino superior: contextos, desafios, possibilidades. Avaliação, v. 14, n. 2, p. 253-266, jul. 2009.

TOMMASINO, H. Extensión e Integralidad: Potencialidades y Desafios para las Universidades Publicas. In: Escuela De Verano De Extensión Universitaria: Extensión e Integralidade. Metodologias y practicas integrales en territorio. Montevideo: Ed. Universidad de la República, 2015.

UNILA. Universidade Federal da Integração LatinoAmericana. Portaria $n^{\circ}$ 076/2011. Institui o Programa de Bolsas de Extensão. Foz do Iguaçu, PR: UNILA, 2011.

UNILA. Universidade Federal da Integração LatinoAmericana. Relatório de gestão do exercício de 2011. Foz do Iguaçu, PR: UNILA, 2011. Disponível em: < http://unila.edu.br/sites/default/files/files/Relatorio\%20de\%20G est\%C3\%A3o\%20UNILA\%202011(1).pdf > Acesso em: 12 fev. 2015 .

UNILA. Universidade Federal da Integração LatinoAmericana. Relatório de gestão do exercício de 2012. Foz do Iguaçu, PR: UNILA, 2013a. Disponível em: < https://unila.edu.br/sites/default/files/files/Relatorio\%20de\%20 Gest\%C3\%A3o\%20UNILA\%202012(1).pdf > Acesso em: 12 fev. 2015.

UNILA. Universidade Federal da Integração LatinoAmericana. Regimento Geral da Universidade. Foz do Iguaçu, PR: UNILA, 2013b. Disponível em: < https://www.unila.edu.br/sites/default/files/files/REGIMENTO \%20GERAL \%20UNILA\%20aprovado\%20no\%20Conselho\%2 0em\%2007_06_2013(1)(1).pdf > Acesso em 22 dez. 2015.

UNILA. Universidade Federal da Integração LatinoAmericana/ Comissão Própria de Avaliação. Relatório de Autoavaliação Institucional 2010-2012. Foz do Iguaçu, PR: UNILA, 2014a. Disponível em: < https://www.unila.edu.br/sites/default/files/files/relatorio\%20fin al\%20CPA\%202010\%202012.pdf > Acesso em 22 dez. 2015.
UNILA. Universidade Federal da Integração LatinoAmericana. Política de Extensão Universitária da UNILA. Foz do Iguaçu, PR: UNILA, 2014b. Disponível em: < https://unila.edu.br/sites/default/files/files/POL\%C3\%8DTICA \%20DE\%20EXTENS\%C3\%830\%202014(1).pdf > Acesso em 23 jan. 2015.

UNILA. Universidade Federal da Integração LatinoAmericana. Pró-Reitoria de Extensão. Relatório de Gestão do exerc'cio de 2014. Foz do Iguaçu, PR, UNILA, 2015. Disponível em: < https://www.unila.edu.br/sites/ default/files/files/Relatorio de Gestao 2014 - UNILA _versao_5_8.pdf > Acesso em 22 dez. 2015.

***

Como citar este artigo:

SOUZA, A. M.; PEREIRA, N. F. F. Escrevendo os Caminhos da Extensão Universitária na UNILA. Revista Brasileira de Extensão Universitária, v. 6, n. 2, p. 77-85, 2015. Disponível em:

$\langle\underline{\text { https://periodicos.uffs.edu.br/index.php/RBEU/article/view/20 }}$ $\underline{62 / \mathrm{pdf}}>$ 